\title{
Research on the Prediction Model of Shield Advancement Rate in Sandy Cobble Ground of Beijing
}

\author{
Qing He $\mathbb{D}^{1},{ }^{1}$ Liying Xu, ${ }^{2}$ Zhiyong Yang $\mathbb{D}^{1},{ }^{1}$ Weiqiang Qi ${ }^{1},{ }^{1}$ Zhigang Zhang, ${ }^{1}$ and Ziyu Shen ${ }^{1}$ \\ ${ }^{1}$ School of Mechanics and Civil Engineering, China University of Mining and Technology-Beijing, Beijing 100083, China \\ ${ }^{2}$ Fujian Institute of Geological Engineering, Fuzhou 350001, Fujian, China \\ Correspondence should be addressed to Zhiyong Yang; yangzy1010@126.com
}

Received 7 December 2020; Revised 17 April 2021; Accepted 14 May 2021; Published 27 May 2021

Academic Editor: André Furtado

Copyright $\odot 2021$ Qing He et al. This is an open access article distributed under the Creative Commons Attribution License, which permits unrestricted use, distribution, and reproduction in any medium, provided the original work is properly cited.

\begin{abstract}
The long distance and tight construction period of the earth pressure balance shield tunneling in Beijing sandy cobble ground have a very positive impact on grasping the construction progress and improving the organization efficiency. Based on the real-time monitoring data of on-site earth pressure, cutter head speed, total thrust, screw conveyor speed, and cutter head torque, this study investigated the correlation between the shield advancement rate and the above parameters based on multiple nonlinear regression analysis method, which lay down the foundation of shield advancement rate prediction. The prediction model achieved satisfactory results and was further applied to an airport project. The results show that it is of guiding significance to use multiple regression method to establish shield prediction model and put forward the best advancement parameters to ensure the construction progress. The order in which the four operational parameters affect the advancement rate is total thrust, cutter head torque, screw conveyor speed, and cutter head speed. When the advancement time is greater than 57 min, the average advancement rate and daily progress are highly positively correlated. The research provides a reliable basis for the advancement rate prediction, safety control, and parameter optimization of shield advancement in similar ground.
\end{abstract}

\section{Introduction}

With the continuous expansion of urban scale in China, urban rail transit is developing more quickly and efficiently, and large-diameter, long-distance shield tunnels have been more widely used. These tunnel shields have long advancement distances and tight construction cycles, which requires higher standards for the corresponding construction organization and management. In order to better control the tunneling progress, the advancement rate can be predicted according to the existing experience and operational parameters to ensure that the shield tunneling is fast and efficient.

As China's most important political and cultural center, Beijing has developed rapidly in underground transportation during recent years. The main components of Beijing sandy cobble ground are weakly weathered pebble particles with high compressive strength and large, soft, easy-flowing sand [1]. The particles are in point-to-point contacts and are sensitive to external reactions. Faced with the complexity and uncertainty of engineering geological conditions in this stratum $[2,3]$, the establishment of shield advancement rate prediction models is particularly important in order to ensure safety, control surface settlement, and construction progress. Considerably, shield advancement rate control depends more on manual construction operations [4]. Through the analysis of operational parameters, it is possible to better quantify the level of construction personnel and achieve rate prediction. By proposing the evaluation formula of Tunnel Boring Machine (TBM) index related to torque, thrust, and penetration, a prediction model is obtained [5], which can guarantee that the shield advances at high rate and safely. During the advancement of the Bangkok Metro [4], a certain relationship between the advancement rate and the earth pressure was proposed. Through ground monitoring, the influence of the earth bunker pressure and grouting pressure on the shield advancement rate was discussed [6]. 
Based on numerical simulation and classical theoretical calculations, the shield advancement process has been extensively studied. Through the Gaussian curve settlement trough theory and finite element simulation, the impact of shield tunneling on ground settlement also has been fully explored [7-9]. Some previous researches shed light on the dynamic response of tunnel advancement [10-13]. In addition, artificial intelligence methods are gradually being applied to underground engineering [14-17]. However, the influence of human factors on operational parameters is difficult to consider [18]; thus, it is normally not considered for the prediction of shield rate.

Therefore, more and more researches try to explain the relationship between operational parameters through parameter analysis and establishing predictive models [19-22]. Through the analysis of TBM design parameters [23], the relationships between diameter and installation thrust, cutter head torque, total weight, cutter head speed, and number of disc cutters, and the upper and lower limits of the predicted advancement rate were provided. Based on a Turkish project [24], big data research was carried out on the four important parameters of cutter head speed, cutter head torque, thrust, and advancement rate during the TBM advancement process, which can comprehensively predict the tunnel geological conditions. After processing the advancement data, it can accurately predict the axial attitude deviation of the shield and provide a correction method [25]. Taking the Shenzhen Metro as an example [26], based on five popular artificial intelligence methods, starting from parameter correlation analysis, inputting geological parameters and operational parameters, an accurate and flexible prediction model is obtained. The model was established by the method of evolutionary hybrid neural network and applied to Guangzhou Metro Line 9. At the same time, a partial sensitivity derivatives analysis method was used to quantitatively evaluate the relevant factors that affect the settlement of the shield construction [16]. The calculation speed is fast, and the prediction effect is good. During the advancement process in the Shenzhen hard rock formation, the influences of geological indicators such as uniaxial compressive strength (UCS), Brazilian tensile strength (BTS), and Cerchar abrasivity index (CAI), as well as the advancement rate and rotation speed on tool wear, are analyzed [27], which provides a reference for rate prediction. The above studies provide enlightening methods on how to construct the shield advancement prediction model.

At present, there are few studies on the prediction model of tunneling performance of long-distance shield tunneling on sandy cobble ground. Operational parameters and advancement rate clearly show a nonlinear relationship $[23,28]$, and there are few studies on the use of nonlinear regression methods to deal with shield advancement. According to the long-distance rapid advancement requirements of the new airport line, combined with the field measured data, the shield advancement prediction model is obtained by the multiple regression method, which is simple and reliable. Through statistical analysis of a large amount of data, the best range of shield advancement is summarized, and the different effects of operational parameters on the progress rate are quantitatively compared, which is highly practical. In addition, the relationship between advancement rate and daily progress is effectively discussed. This research provides a useful reference for the prediction of construction speed and schedule control.

\section{Engineering Background}

2.1. Project Overview. The Beijing New Airport Line, which mainly passes through sand and pebble formations, is constructed using large-diameter earth pressure balance shields. The tunneling project has the characteristics of tight construction period, long shield crossing of pebble formations, long interval tunnels, and serious construction organization difficulty.

As shown in Figure 1, section 2 3 of 07-bid is the longest shield section of the New Airport Line as well as the longest shield section of the Beijing Subway, with a total length of $3847 \mathrm{~m}$. Shield starts from No. 2 receiving shaft and receives from No. 3 receiving shaft. The right line is the advance line, which started on November 10, 2017, and the left line is the rear line, which started 20 days after the start of the right line. The two lines were finally completed on August 28, 2018, and began operation on September 26, 2019.

In the area between No. 2 receiving shaft and No. 3 receiving shaft project, the left line has a total length of $3832.39 \mathrm{~m}$ and the right line has a total length of $3847.44 \mathrm{~m}$, which is the longest shield section of the entire line. Simultaneous construction is conducted using two earth pressure balance shield machines with outer diameter of $9150 \mathrm{~mm}$. The soil thickness of the shield tunnel is 9.3-15.1 $\mathrm{m}$, and the water level is below the ground, between 3.01 and $7.23 \mathrm{~m}$. The maximum slope is $5.9 \%$, and the interval is about $3840 \mathrm{~m}$. The tunnel lining segment is prefabricated reinforced concrete structure. The outer diameter of the tunnel segment is $8800 \mathrm{~mm}$, the thickness is $450 \mathrm{~mm}$, the inner diameter is $7900 \mathrm{~mm}$, and the width is $1600 \mathrm{~mm}$.

The earth pressure balance shield adopts a spoke cutter head with an aperture ratio of $60 \%$. The cutter head is mainly composed of a rim, spokes, and cutters arranged on the spokes. Figure 2 shows the layout of the shield cutter head obtained from the field investigation. The effect of tool layout is shown in Figure 2. The high-strength and highrigidity design of the main structure can ensure that the cutter head adapts to the working conditions of high torque and high thrust during construction, which can reduce tool wear and achieve efficient tunneling [29]. Table 1 summarizes the specifications of TBM in detail.

2.2. Geological Survey of the Test Section. In order to eliminate the construction effect on the existing superstructure, the section with a large burial depth and no surrounding buildings (structures) was selected for the test.

At the same time, in order to reasonably control the construction progress and obtain the reasonable range of advancement rate, earth pressure, cutter head speed, torque, total thrust, and screw conveyor speed during advancement, 


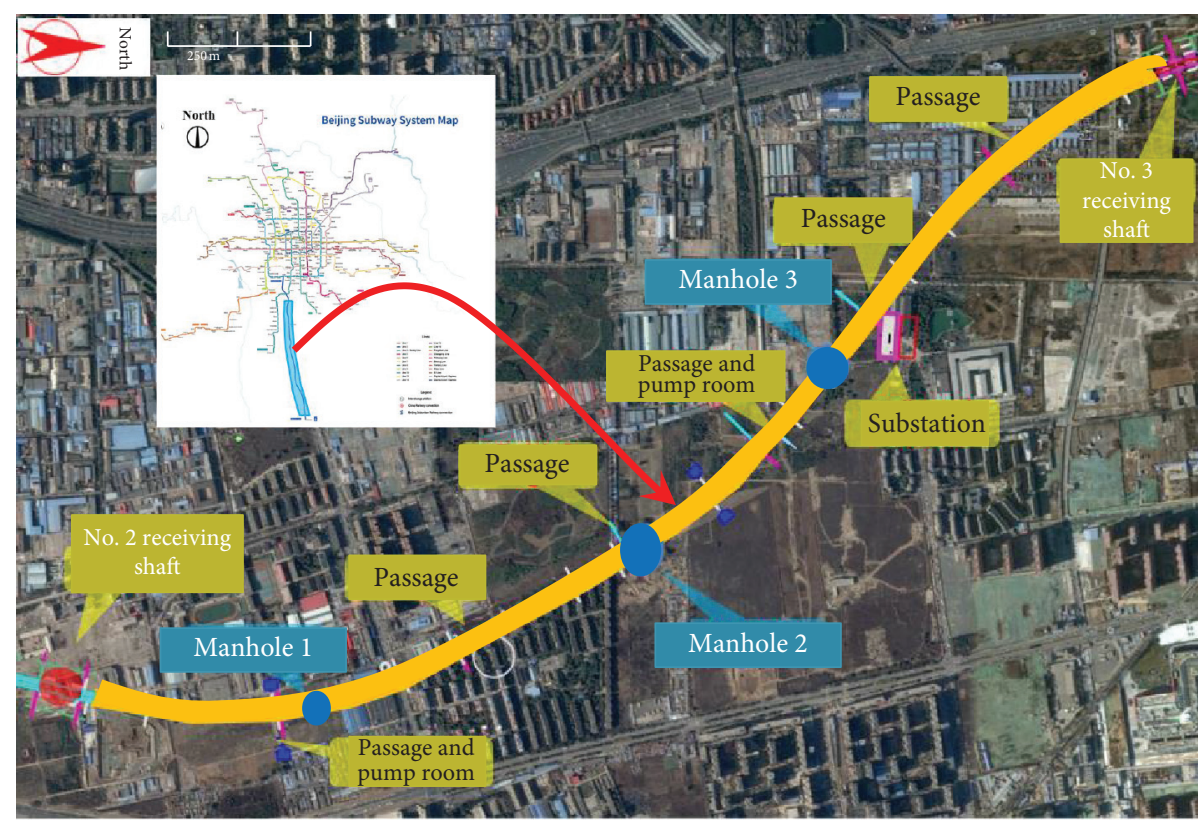

FIGURE 1: Location of the studied tunnel.

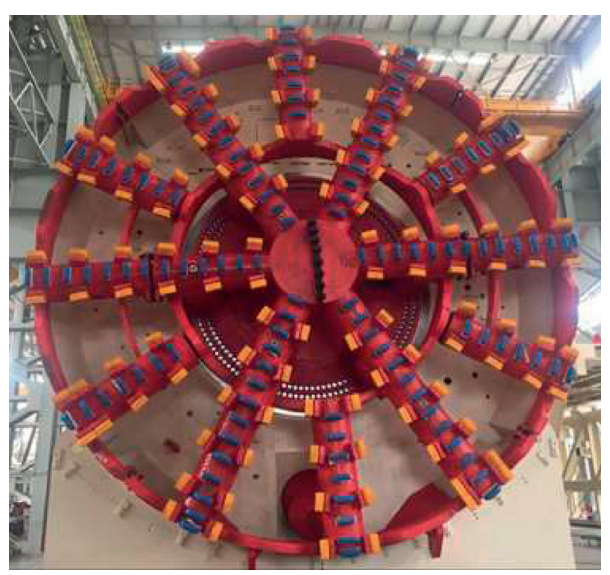

Figure 2: Cutter layout.

TABLE 1: Specification of operated TBM.

Description

Manufacturer

Maximum advancement rate

Maximum total thrust

Maximum cutter head torque

Screw conveyor speed range

Cutting diameter

Gross weight

Installed power

Type

Center tool

Front cutter

Cutter

Gauge knife

Cutter head opening rate

Cutter head drive system
Specification

China Railway Engineering Equipment Group Co., Ltd

$80 \mathrm{~mm} / \mathrm{min}$

$81853 \mathrm{kN}$

$249 \mathrm{kN} \cdot \mathrm{m}$

$0 \sim 20 \mathrm{r} / \mathrm{min}$

$9150 \mathrm{~mm}$

$1250 \mathrm{t}$

$4500 \mathrm{~kW}$

Spoke type

$$
1
$$

75 high shell knives

51 low shell knives

120

$22 \times 3$

$60 \%$

$12 \times 250 \mathrm{~kW}$ 
the right line shield tunneling 85-184 ring, which is referred to as "test section," was selected to conduct the test.

As shown in Figure 3, the tunnel test section mainly passes through silt (4)2, silty sand (4) 3 , and pebble gravel (5). The wear of the cutter discs tunneling in this kind of formation is obvious [30]. The physical and mechanical indexes of the main soil layers in the test section are shown in Table 2.

Samples from on-site drilling rigs are taken to laboratory tests to obtain more reliable engineering geological parameters. The density is measured by the ring knife method to calculate the bulk density; the internal friction angle and cohesion are measured by the direct shear test, and the lateral pressure coefficient is measured by the static lateral pressure coefficient consolidation instrument.

\section{Shield Advancement Parameter Analysis}

3.1. Parameter Statistics. In the process of shield tunneling in Beijing, the construction management unit put forward a clear control range for soil pressure, total thrust, and cutter head torque. The advancement rate is the product of the cutter head speed and penetration, while the screw conveyor speed reflects the advancement capacity. In terms of strength and weakness, it can be said that the above 6 parameters are the most concerned parameters among the hundreds of shield parameters. It is more convenient to apply the parameters that have been focused on during construction. During on-site construction, the on-site sensor sometimes fails, and the parameter suddenly drops to zero, such as earth pressure, or has a negative value, such as the total thrust. The appearance of these outliers has no regularity, so removing them can improve the efficiency of analysis and reduce the influence of outliers on model prediction.

Based on on-site computer real-time monitoring data, statistics of earth pressure, penetration, cutter head speed, total thrust, cutter head torque, and screw conveyor speed during shield advancement are provided in Figure 4. An optimal range for the advancement parameters can be concluded as follows: the earth pressure is maintained at $0.6-1.0$ bar, the penetration is concentrated at $25-35 \mathrm{~mm} /$ $\mathrm{r}$, the cutter head speed is concentrated at $1.6-1.8 \mathrm{rpm}$, the total thrust is set at $20000-30000 \mathrm{kN}$, the speed of the screw conveyor is relatively stable at $7-10 \mathrm{rpm}$, and the torque value is concentrated at $9000-12000 \mathrm{kN} \cdot \mathrm{m}$.

With the tunneling of the shield tunnel (ring 85-184), the changes of operational parameters including earth pressure (EP), penetration (PR), cutter head speed (CHS), total thrust (TT), screw conveyor speed (SCS), and cutter head torque (CHT) are shown in Figure 5.

3.2. Sensitivity Analysis. In order to conduct an in-depth sensitivity analysis, the "correlation coefficient" is applied to evaluate the correlation between the operational parameters and the advancement rate. The most commonly used correlation coefficient is the Pearson correlation coefficient, shown in the following equation:

$$
r=\frac{\sum_{i=1}^{n}\left(x_{i}-\bar{x}\right)\left(y_{i}-\bar{y}\right)}{\sqrt{\sum_{i=1}^{n}\left(x_{i}-\bar{x}\right) \sum_{i=1}^{n}\left(y_{i}-\bar{y}\right)}} \quad(i=1,2, \ldots, m),
$$

where $n$ is the sample size; $x_{i}$ and $y_{i}$ are the sampling points. $\bar{x}$ and $\bar{y}$ are the average values. Generally, when the correlation coefficient is greater than 0.4 , there is a relatively strong correlation between the parameters; when the value of the correlation coefficient is greater than 0.7 , there is a strong correlation between the parameters. The occurrence of outliers will interfere with the analysis of related parameters, so the outliers would be deleted before the parameter analysis.

The correlation coefficient between the parameters is shown in Figure 6.

The following can be seen from Figure 6: (1) The correlation coefficient between $\mathrm{AR}$ and $\mathrm{P}$ is about 0.97 , showing a linear positive correlation. (2) The correlation coefficient between AR and TT is about -0.53 , showing a relatively strong negative correlation. This shows that after TT reaches a certain value in the sandy cobble ground, increasing the TT will even have a negative effect on the advancement of the shield. (3) The correlation coefficients between SCS, CHT, and AR are 0.53 and 0.43 , respectively, indicating that there is a good positive correlation between SCS, CHT, and AR.

3.3. Determining the Correlation between Parameters. The parameters about shield construction are recorded and stored every $10 \mathrm{~s}$. To avoid the huge workloads of sorting all the monitoring results, the data are divided into groups, and the advancement rate is represented by the average value. The scatter diagrams of the relationship between the rate and other parameters are presented in Figure 7. Note that all the calculations are based on absolute values.

It can be seen that the advancement rate of the test section only shows a good linear relationship with the penetration. After analysis, it was found that the other five parameters gradually increased, and the advancement rate increased accordingly. After reaching the inflection point, the growth rate obviously slows down or even gradually decreases. It can be seen that there existed optimal values for the five important parameters. When these parameters are controlled in the optimal interval, it can achieve fast and long distance tunneling with safety.

Based on the above analysis, the advancement parameters are determined as follows: the earth pressure is maintained at $0.7 \sim 0.9$ bar, the speed is $1.675 \sim 1.725 \mathrm{rpm}$, the thrust is set to $21000 \sim 24000 \mathrm{kN}$, and the torque is $10000 \sim 11000 \mathrm{kN} \cdot \mathrm{m}$. It is worth noting that the speed of the screw conveyor should be controlled at about 9 10 rpm. When the advancement rate changes, the speed of the screw conveyor should be adjusted accordingly in order to maintain the pressure in the soil bunker.

\section{Establishment and Validation of the Prediction Model for Advancement Rate}

4.1. Establishment of the Advancement Rate Prediction Model. The multiple regression analysis method is widely used when analyzing more than two variables. The Taylor 


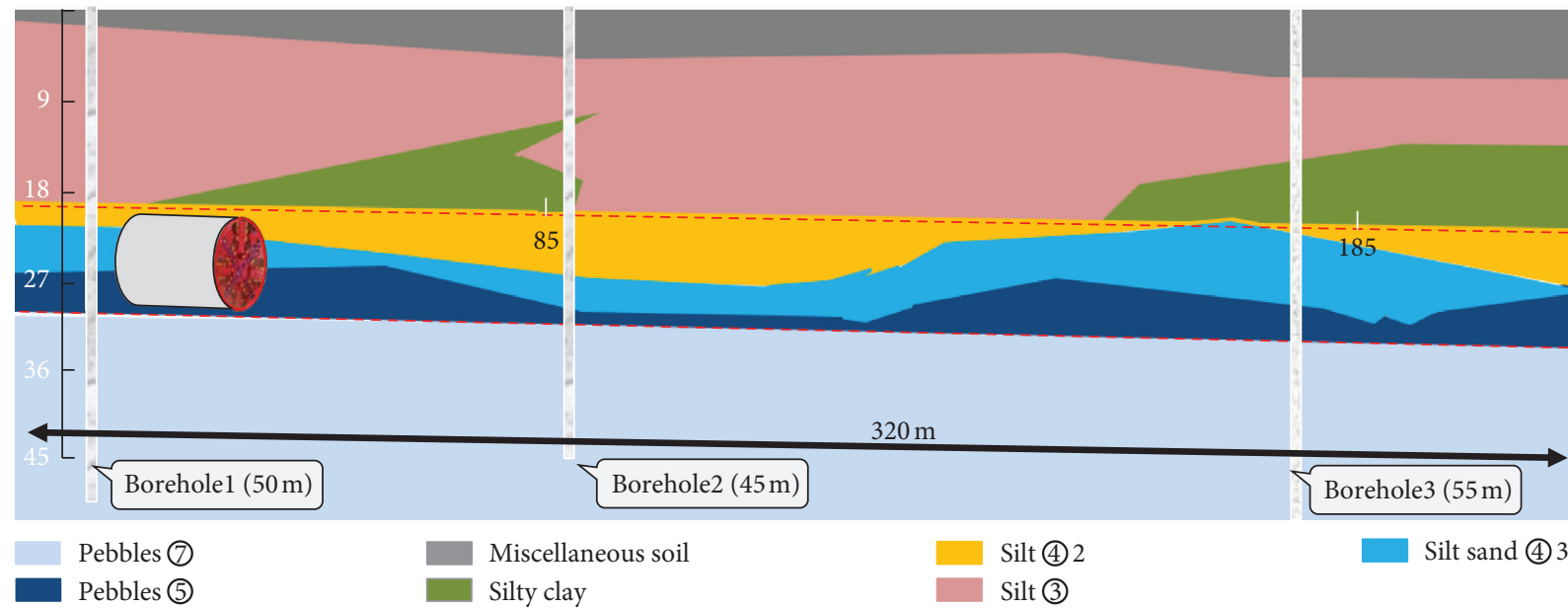

Figure 3: Main strata of test section.

TABLE 2: Physical and mechanical indicators of main crossing soil layer in test section.

\begin{tabular}{lcccc}
\hline Soil layer & Buried (m) & $\gamma\left(\mathrm{kN} / \mathrm{m}^{3}\right)$ & $c(\mathrm{kPa})$ & $\varphi\left(^{\circ}\right)$ \\
\hline Plain fill (1)1 & 0.70 & 18.00 & 0.00 & 10.00 \\
Silt-fine sand (2)3 & 3.80 & 19.00 & 0.00 & 0.00 \\
Silt (2) & 1.50 & 19.30 & 10.00 & 20.00 \\
Silt-fine sand (2)3 & 6.10 & 19.00 & 0.00 & 20.00 \\
Silt (3) & 4.80 & 19.80 & 22.00 & 0.40 \\
Fine sand-sand (4)3 & 10.70 & 20.30 & 0.00 & 21.90 \\
Medium sand-fine sand (4)2 & 7.40 & 20.50 & 0.00 & 28.00 \\
Boulders-pebbles (5) & 14.60 & 21.00 & 0.00 & 32.00 \\
Pebble-round gravel (7) & 16.60 & 21.20 & 0.34 \\
\end{tabular}

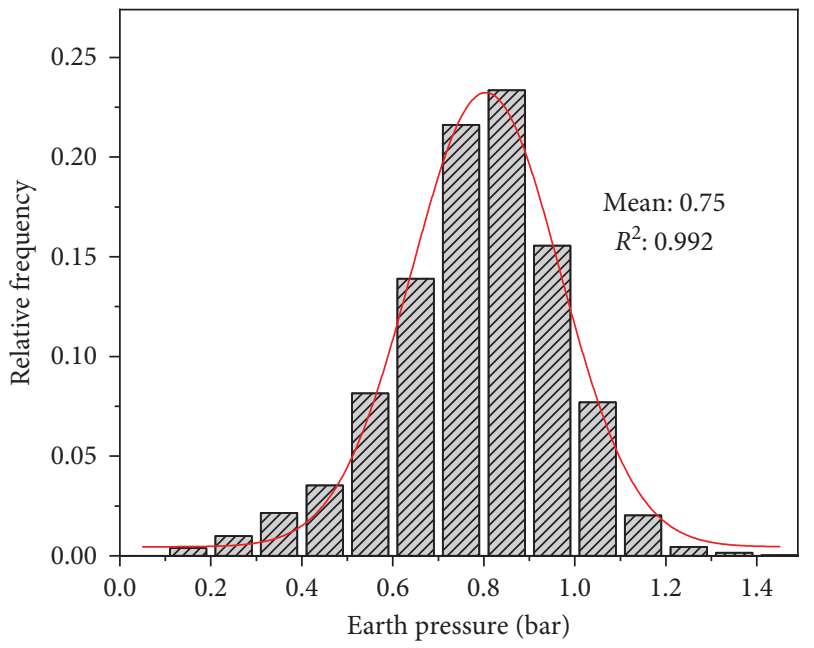

(a)

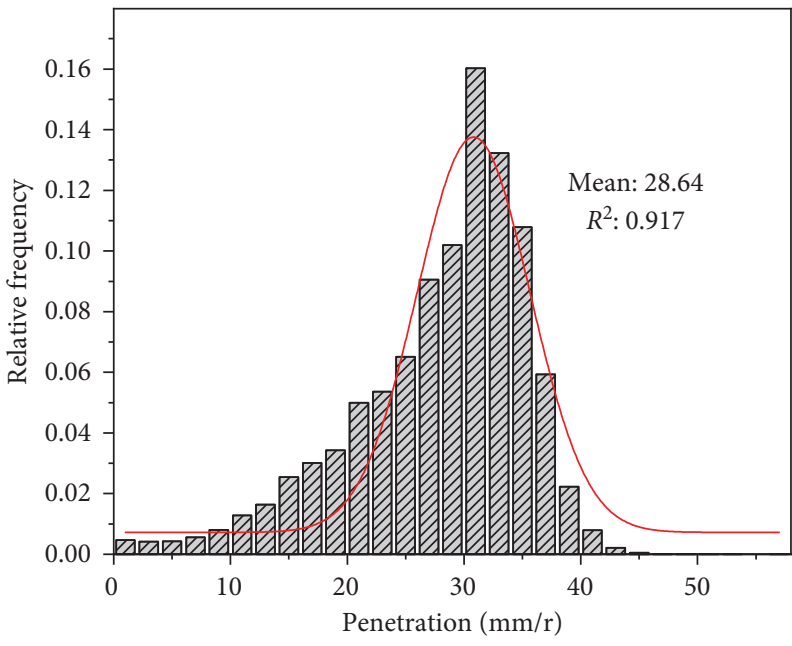

(b)

Figure 4: Continued. 


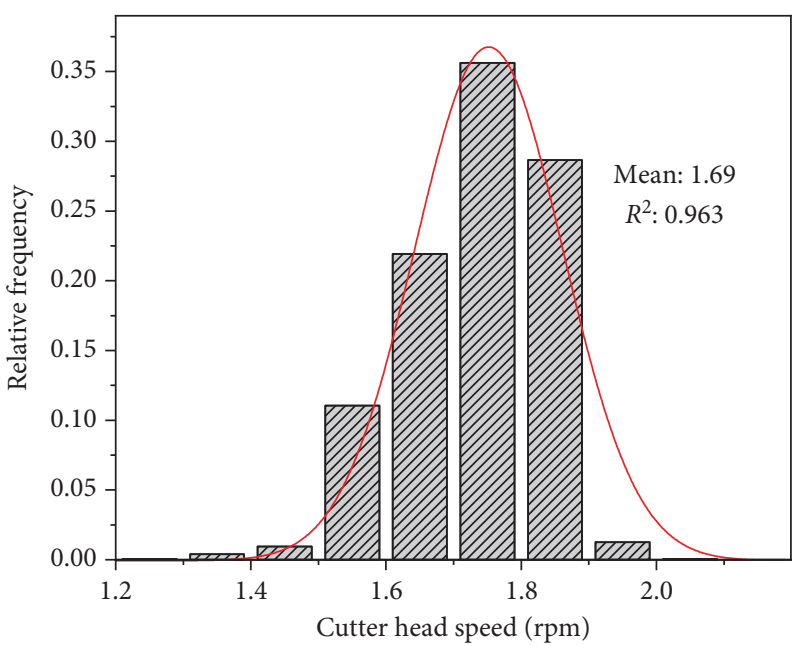

(c)

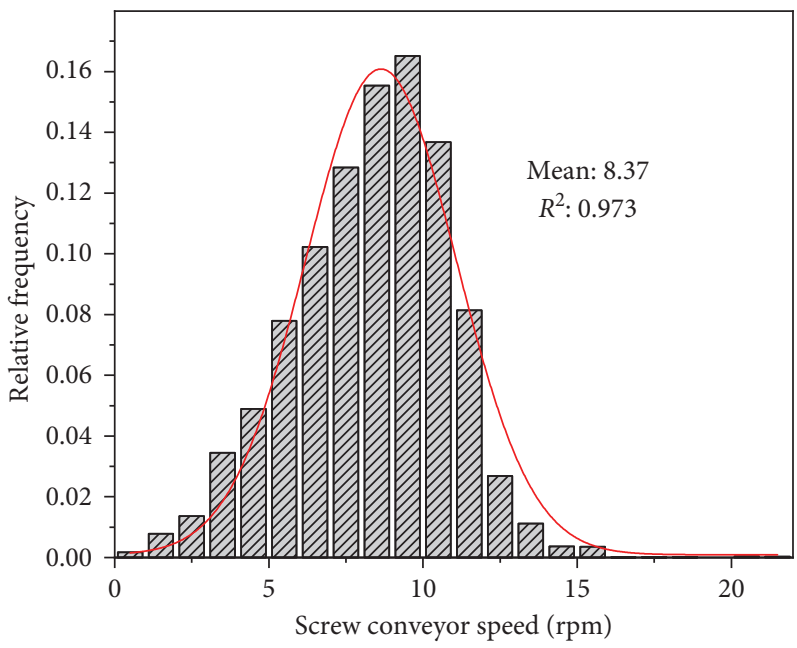

(e)

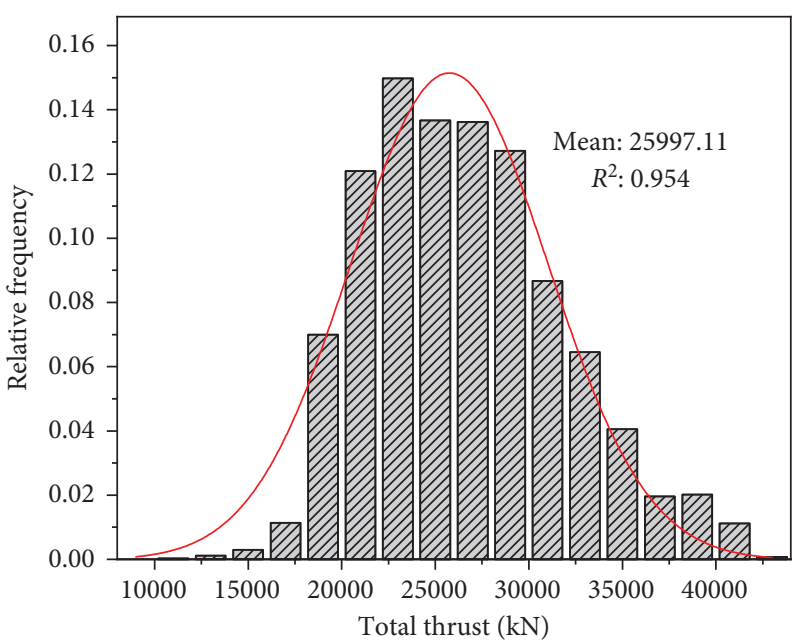

(d)

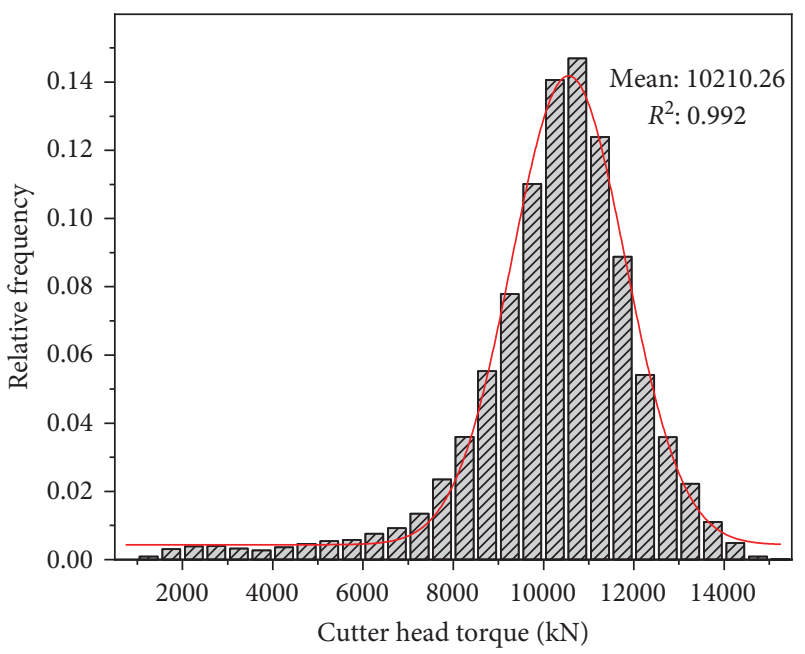

(f)

FIgURE 4: Test section parameter statistics.

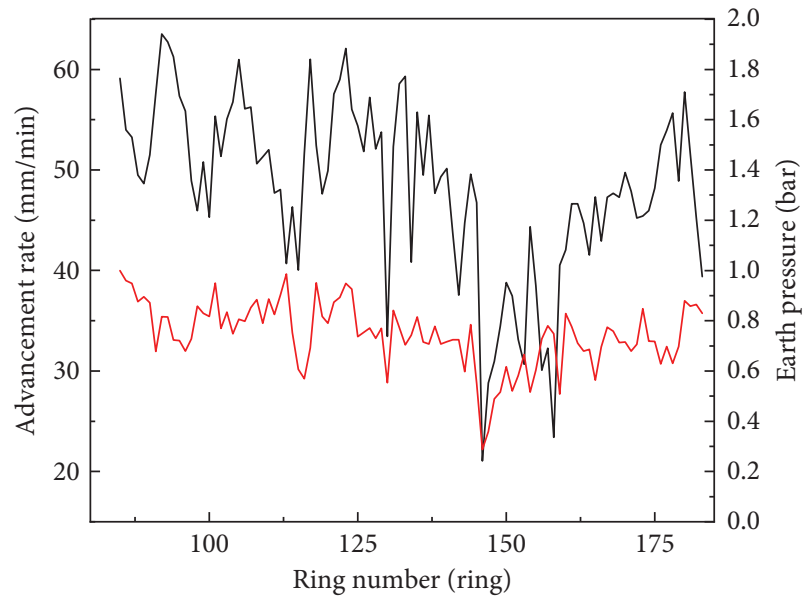

_ Advancement rate _ Earth pressure

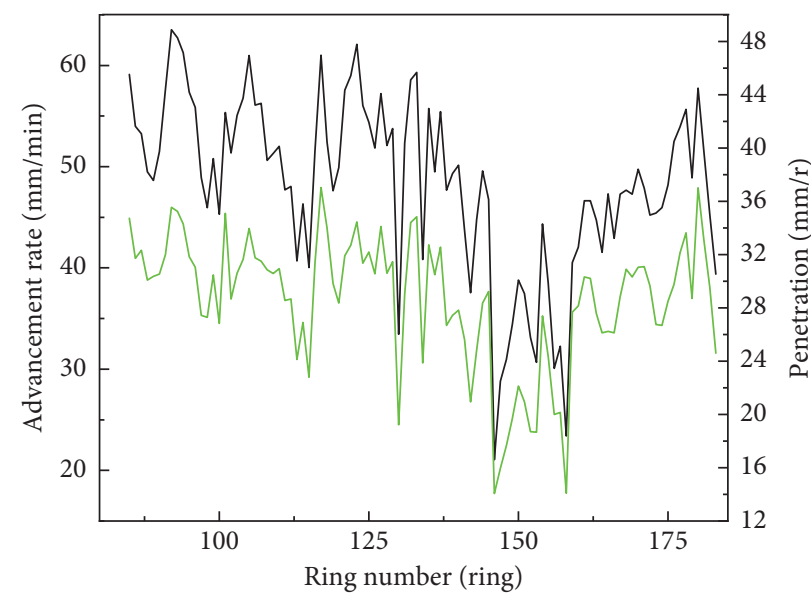

- Advancement rate Penetration

(a)

FIgURE 5: Continued. 


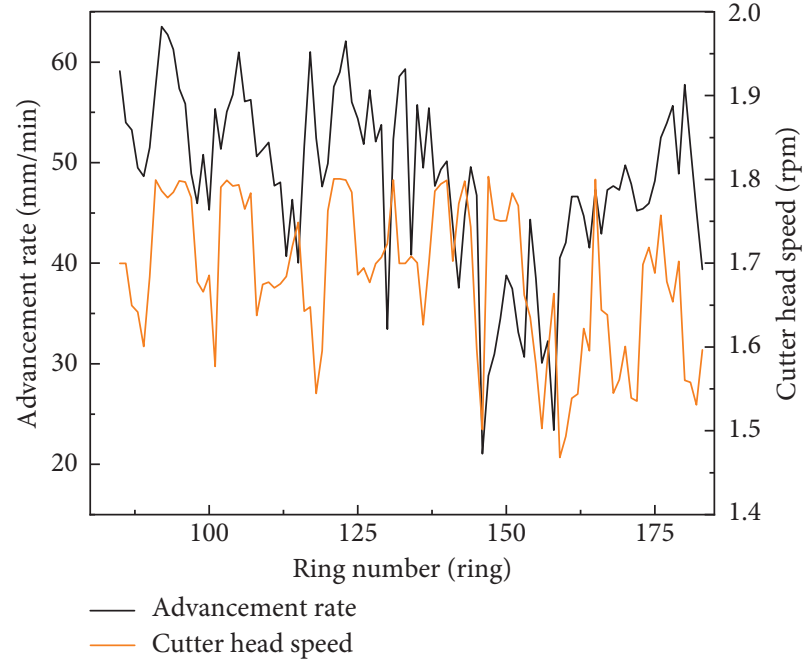

(c)

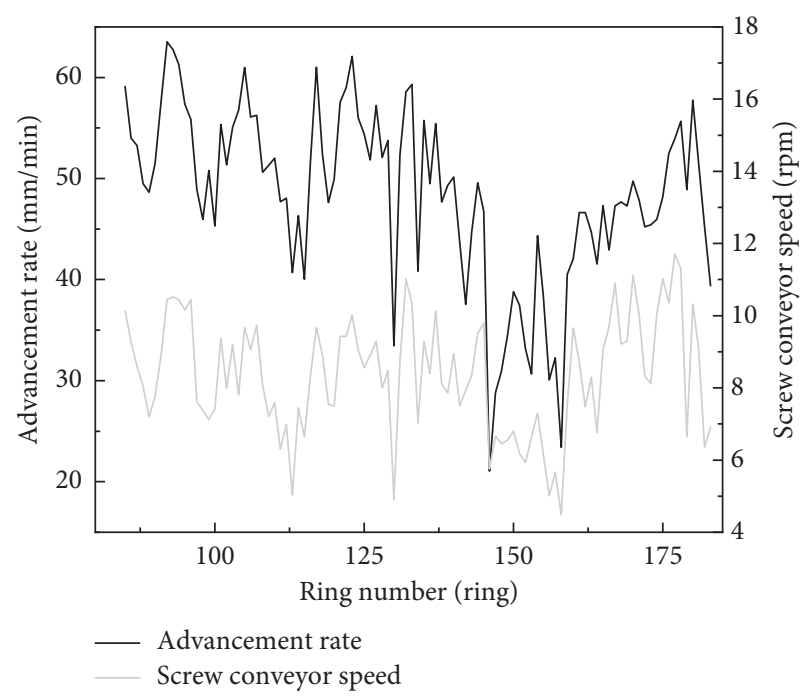

(e)

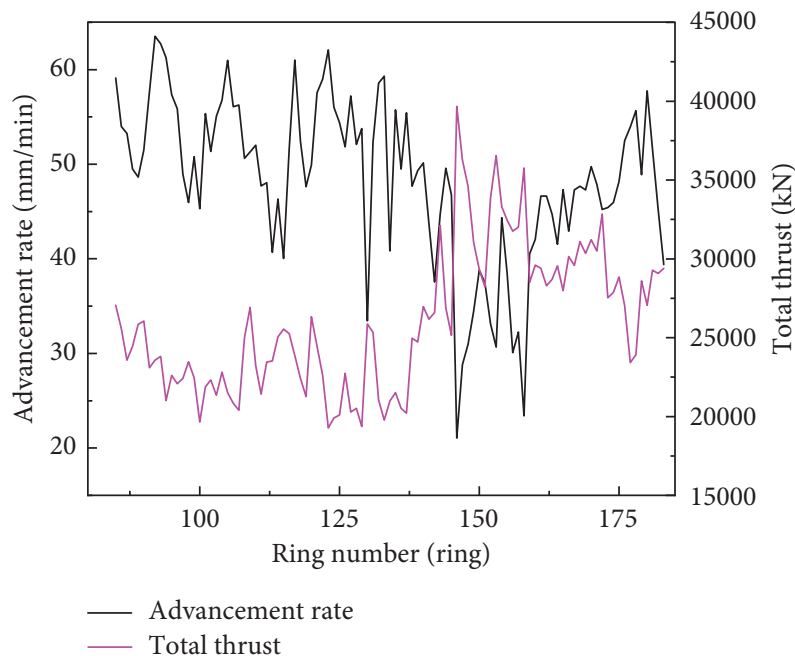

(d)

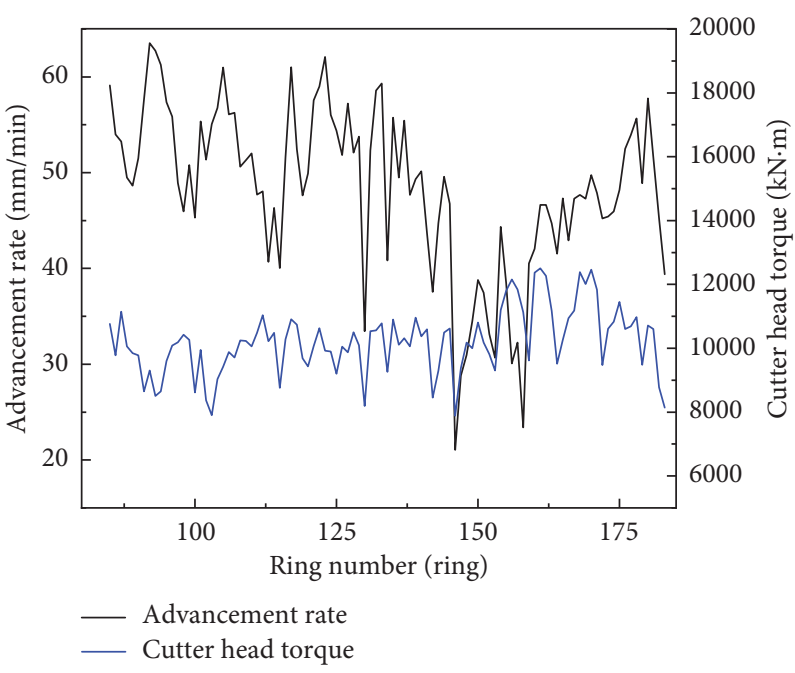

(f)

FIGURE 5: The change process of each parameter.

expansion infinite approximation regression model is applied to construct the multiple nonlinear regression model:

$$
\begin{aligned}
y= & a_{1} x_{1}+a_{2} x_{2}+a_{3} x_{3}+a_{4} x_{1}^{2}+a_{5} x_{2}^{2}+a_{6} x_{3}^{2} \\
& +a_{7} x_{1} x_{2}+a_{8} x_{1} x_{3}+a_{9} x_{2} x_{3}+\ldots+e,
\end{aligned}
$$

where $a_{i}$ is the unknown parameter and $e$ is the Lagrange remainder.

Since the penetration degree shows a linear relationship with the advancement rate, it is not further considered here. Five parameters, cutter head speed, cutter head torque, total thrust of shield, screw conveyor speed, and earth pressure, are selected as independent variables to construct the multivariate nonlinear model. The corresponding symbols and units are shown in Table 3.

Assume that

$$
\begin{aligned}
v= & a_{1} \omega_{1}+a_{2} T+a_{3} F+a_{4} \omega_{2}+a_{5} p+a_{6} \omega_{1}^{2}+a_{7} T^{2} \\
& +a_{8} F^{2}+a_{9} \omega_{2}^{2}+a_{10} p^{2}+a_{11} \omega_{1} T+a_{12} \omega_{1} F+\ldots e .
\end{aligned}
$$

The regression parameters are calculated using SPSS, as shown in Table $4 . R^{2}$ is 0.876 , indicating that the model regression equation fits the sample value well, and $F=14240$ indicates that the fitting effect is significant at the 0.05 level.

Comparing the absolute value of $t$, the order of the influence of the independent variables can be obtained as follows: total thrust $>$ cutter head torque $>$ screw conveyor speed $>$ cutter head speed $>$ earth pressure, which provides the basis for parameter control during the advancement process. By substituting the calculation results into the established model, a prediction model suitable for the advancement rate of the stratum shield during normal construction can be obtained: 


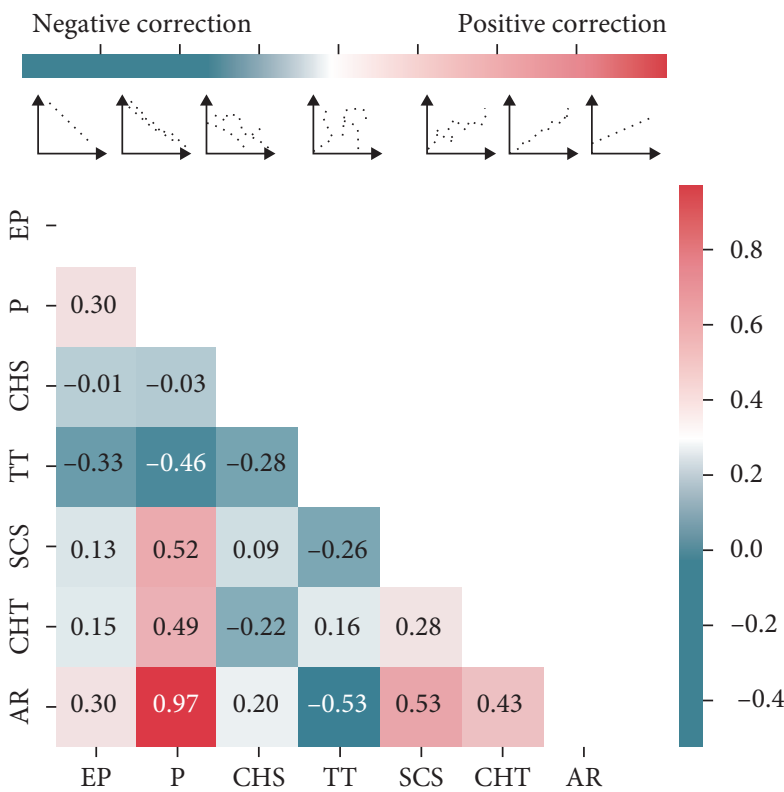

FIgURE 6: Parameter correlation analysis.

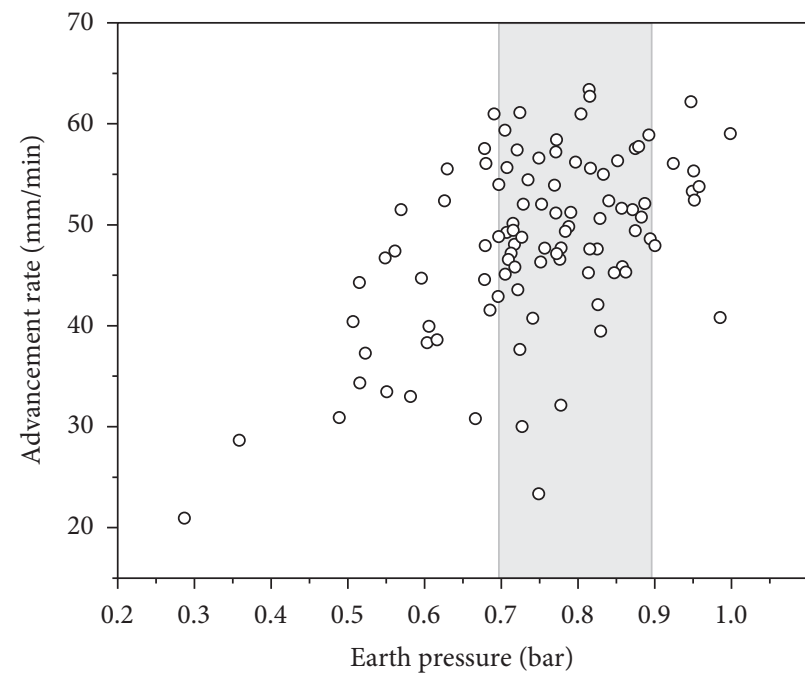

(a)

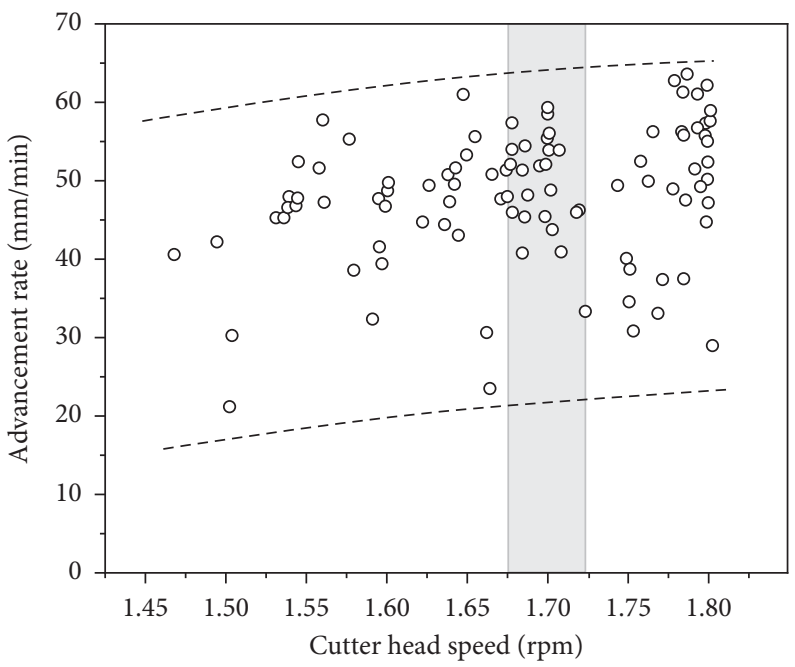

(c)

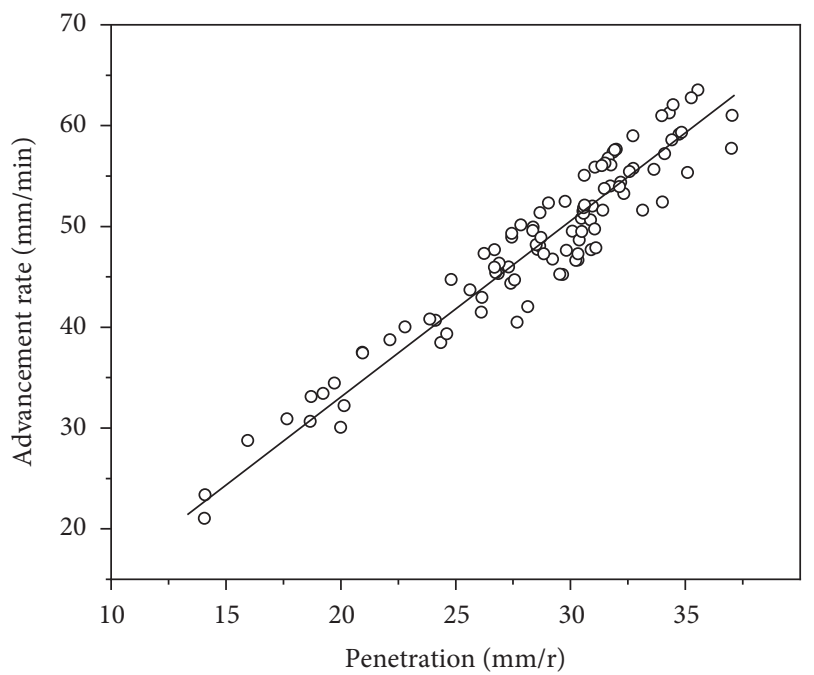

(b)

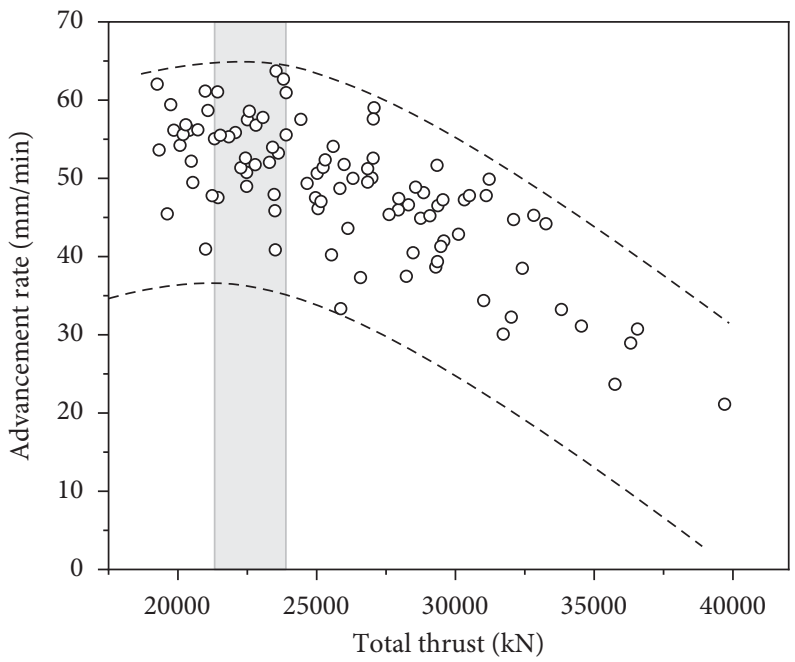

(d)

Figure 7: Continued. 


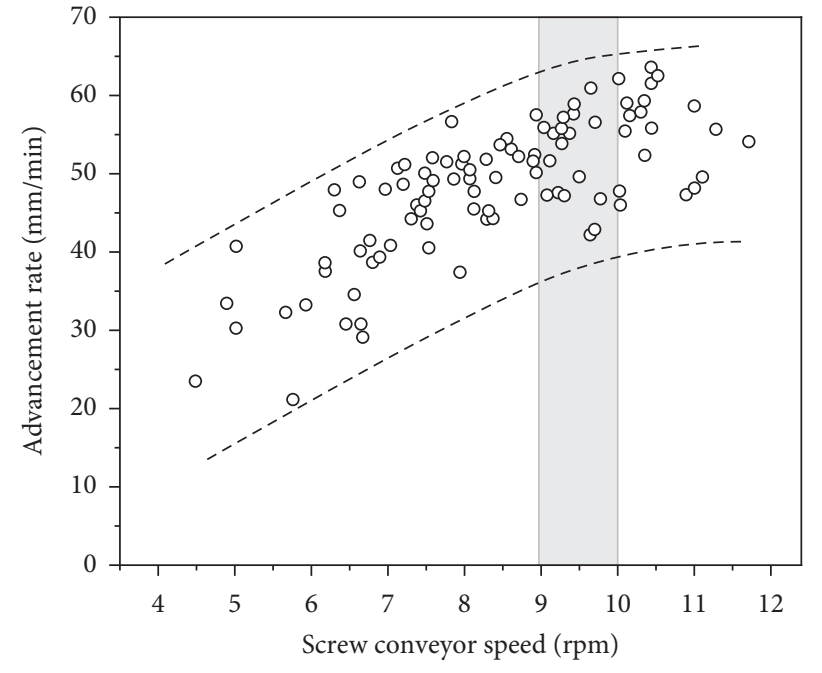

(e)

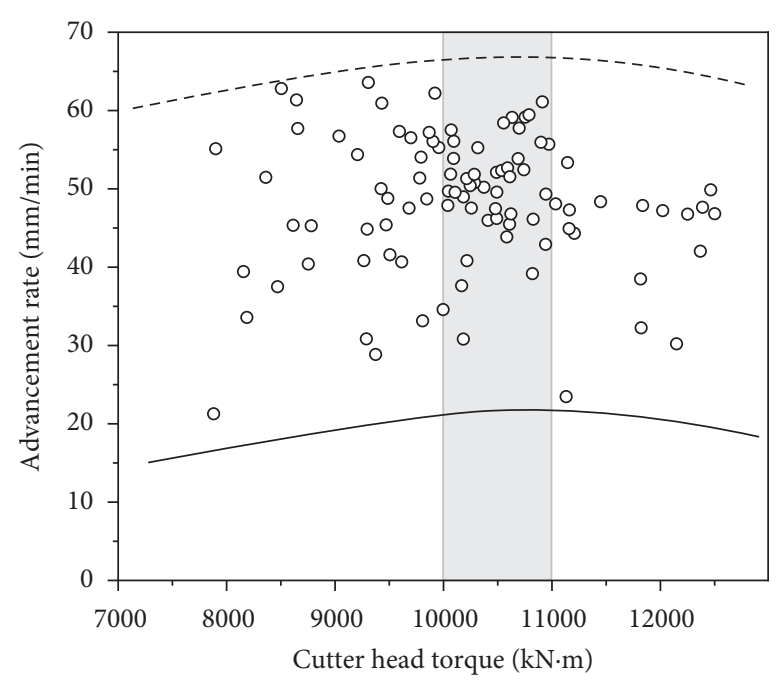

(f)

FIGURE 7: Relationships between operational parameters and advancement rate.

TABle 3: Choice of model regression parameters.

\begin{tabular}{lccccc}
\hline Independent variable & Cutter head speed & Cutter head torque & Total thrust & Screw conveyor speed & Earth pressure \\
\hline Symbol & $\omega_{1}$ & $T$ & $F$ & $\omega_{2}$ & $p$ \\
Unit & $\mathrm{r} \cdot \mathrm{min}^{-1}$ & $\mathrm{kN} \cdot \mathrm{m}$ & $\mathrm{kN}$ & $\mathrm{r} \cdot \mathrm{min}^{-1}$ & $\mathrm{bar}$ \\
\hline
\end{tabular}

TABLE 4: Result of multivariate regression parameters of the model.

\begin{tabular}{|c|c|c|c|c|c|}
\hline \multirow{2}{*}{ Variable } & \multicolumn{2}{|c|}{ Unstandardized coefficient } & \multirow{2}{*}{$\begin{array}{c}\text { Standardized coefficient } \\
\text { Beta }\end{array}$} & \multirow{2}{*}{$t$} & \multirow{2}{*}{ Distinctiveness } \\
\hline & Regression coefficients & Standard error & & & \\
\hline (Constant) & -4.102 & 0.899 & & -4.560 & 0.000 \\
\hline$\omega_{1} T$ & 0.001 & 0.000 & 0.204 & 13.535 & 0.000 \\
\hline$\omega_{1} \omega_{2}$ & 1.676 & 0.059 & 0.528 & 28.402 & 0.000 \\
\hline$F \omega_{2}$ & $-1.726 \times 10^{-5}$ & 0.000 & -0.086 & -7.971 & 0.000 \\
\hline$F p$ & $-4.39 \times 10^{-4}$ & 0.000 & -0.178 & -16.096 & 0.000 \\
\hline$F^{\frac{1}{2}}$ & $-6.700 \times 10^{-8}$ & 0.000 & -1.191 & -99.734 & 0.000 \\
\hline$F$ & 0.003 & 0.000 & 1.714 & 60.253 & 0.000 \\
\hline$\omega_{1}$ & -18.395 & 0.929 & -0.384 & -19.794 & 0.000 \\
\hline$T F$ & $7.944 \times 10^{-8}$ & 0.000 & 0.468 & 29.932 & 0.000 \\
\hline$T^{2}$ & $-1.777 \times 10^{-7}$ & 0.000 & -0.399 & -33.626 & 0.000 \\
\hline$T$ & 0.003 & 0.000 & 0.409 & 24.593 & 0.000 \\
\hline$\omega_{2}$ & -2.298 & 0.111 & -0.427 & -20.615 & 0.000 \\
\hline$\omega_{2} p$ & 1.546 & 0.082 & 0.233 & 18.962 & 0.000 \\
\hline$\omega_{1} F$ & -0.001 & 0.000 & -0.476 & -18.082 & 0.000 \\
\hline$\omega_{1}^{2}$ & 6.966 & 0.395 & 0.289 & 17.655 & 0.000 \\
\hline$\omega_{1} p$ & 3.805 & 0.595 & 0.079 & 6.396 & 0.000 \\
\hline$p^{2}$ & -2.692 & 0.704 & -0.036 & -3.826 & 0.000 \\
\hline$T p$ & $-3.09 \times 10^{-4}$ & 0.000 & -0.043 & -3.554 & 0.000 \\
\hline$T \omega_{2}$ & $1.534 \times 10^{-5}$ & 0.000 & 0.032 & 2.286 & 0.022 \\
\hline$p$ & 2.768 & 1.377 & 0.026 & 2.010 & 0.044 \\
\hline
\end{tabular}




$$
\begin{aligned}
v= & -18.395 \omega_{1}+0.003 T+0.003 F-2.298 \omega_{2}+2.768 p+6.966 \omega_{1}^{2}-(1.777 E-7) T^{2}-(6.700 E-8) F^{2} \\
& -2.692 p^{2}+0.001 \omega_{1} T-0.001 \omega_{1} F+1.676 \omega_{1} \omega_{2}+3.805 \omega_{1} p+(1.534 E-5) T \omega_{2}+(7.944 E-8) T F \\
& -(3.09 E-4) T p-(4.39 E-4) F p-(1.726 E-5) F \omega_{2}+1.546 \omega_{2} p-4.102
\end{aligned}
$$

4.2. Validation of the Advancement Rate Prediction Model. The measured data is used to verify the above rate prediction model, as shown in Figure 8. The correlation coefficient is 0.88 . It can be seen that the actual measured value is generally higher than the fitted data, but it can basically fit the trend of the advancement rate during the construction of the test section. At the same time, if it is a long-distance tunneling prediction, the error will be further reduced [4]. It is believed that the model is suitable for the prediction of the shield advancement rate in sandy cobble ground, and further research can be used as the basis for the shield construction progress prediction and parameter optimization in sandy cobble ground in Beijing.

During the tunneling process, the frequency of the advancement rate of the entire line (including the left and right lines) is recorded. The arrangement is shown in Table 5.

The frequency of the right-line forecast data at $0-50 \mathrm{~mm} /$ min is higher than the measured data, and the frequency of the measured data over $50 \mathrm{~mm} / \mathrm{min}$ is slightly higher than the predicted data, but the overall trend is basically consistent. The frequency of each band is basically the same, and the correlation coefficient is 0.9 . The left and right lines behave similarly, with a correlation coefficient of 0.88 . This shows that the prediction of the advancement rate model is effective and can be applied to the study in sandy cobble ground of the new airport line.

\section{Application of the Advancement Rate Prediction Model}

When the shield advance time is the same, with increasing advance rate, more advancement rings will be set up per day, and the daily progress is better. However, due to the complexity of engineering geology in the actual construction process and the uncertainty of manual operations, it is impossible to guarantee a stable advancement time.

Therefore, the relevant operational parameters of the section 2-3 project of the 07-bid section from January 6th, 2018, to February 2nd, 2018, are recorded, as shown in Table 6. After analyzing the daily progress, maximum rate, minimum rate, average rate, standard deviation, and daily advancement time and removing the outliers, it is shown that the minimum rate and daily progress are not related. This is because the advancement rate continuously changes during the tunneling process, so the minimum value of the advancement rate has no effect on the study of daily progress.

In order to analyze the correlation between the advancement rate and the daily progress clearly, the advancement time is grouped, as shown in Table 7.

Through formula (1), the correlation coefficients of the three experimental groups are analyzed, as shown in Figure 9. The correlation between the parameters in the figure is represented by dark colors, which indicates high correlation, while light colors indicate weak or no correlation. Dark blue indicates strong positive correlation and dark red indicates strong negative correlation. The red font indicates that the correlation coefficient is negative. The linear correlation evaluation is shown in Figure 10.

As shown in Figure 10, when the daily advancement time is less than 30 minutes, there is no correlation between the advancement rate and the daily progress, and there is a strong positive correlation between the advancement time and the daily progress $(r>0.8)$. This indicates that the daily progress is mainly affected by the advancement time when the advancement time is small. When the daily advancement time becomes longer (more than 30 minutes but less than 57 minutes), there is no correlation between the advancement rate, advancement time, and daily progress ( $r$ less than 0.4 ), but there is a strong negative correlation between the standard deviation of the advancement rate and the daily progress $(r<0.8)$. This shows that stable advancement rate will ensure better daily progress. When the daily advancement time is more than 57 minutes, the average rate of advancement and the standard deviation of the advancement rate are positively correlated with the daily progress $(r>0.8)$. This indicates that when the advancement rate is at a relatively high rate, the daily progress is significantly increased.

The graph not only shows the correlation between each parameter and the daily progress but also shows the correlation between each parameter. Analyzing the correlation of these parameters is helpful for a deeper understanding of their impacts on the daily progress. As the advancement time becomes longer, the influence of the maximum advancement rate on the average value becomes more obvious ( $r$ increased from -0.41 to 0.99 ). The daily advancement time has a significant influence on the average rate. With increasing digging time, the effect on the average rate changes from positively related to irrelevant ( $r$ decreased from 0.70 to -0.14 ). The standard deviation of the rate becomes larger with the daily advancing time, and its correlation with the average rate changes from negative to positive ( $r$ increased from -0.77 to 1.00 ). The relationships among the parameters that affect the daily progress are complicated and nonlinear. Since the correlation coefficient analysis only considers linear correlation, trend analysis is added.

The construction period of the new airport line is tight, and the advancement length is large. The actual advancement time is longer, which meets the safety and construction requirements. When the advancement time is long (more than 57 minutes), the average advancement rate and daily progress are highly positively correlated. Therefore, the construction progress of the entire line is recorded, and the shield prediction model is used. The advancement progress 


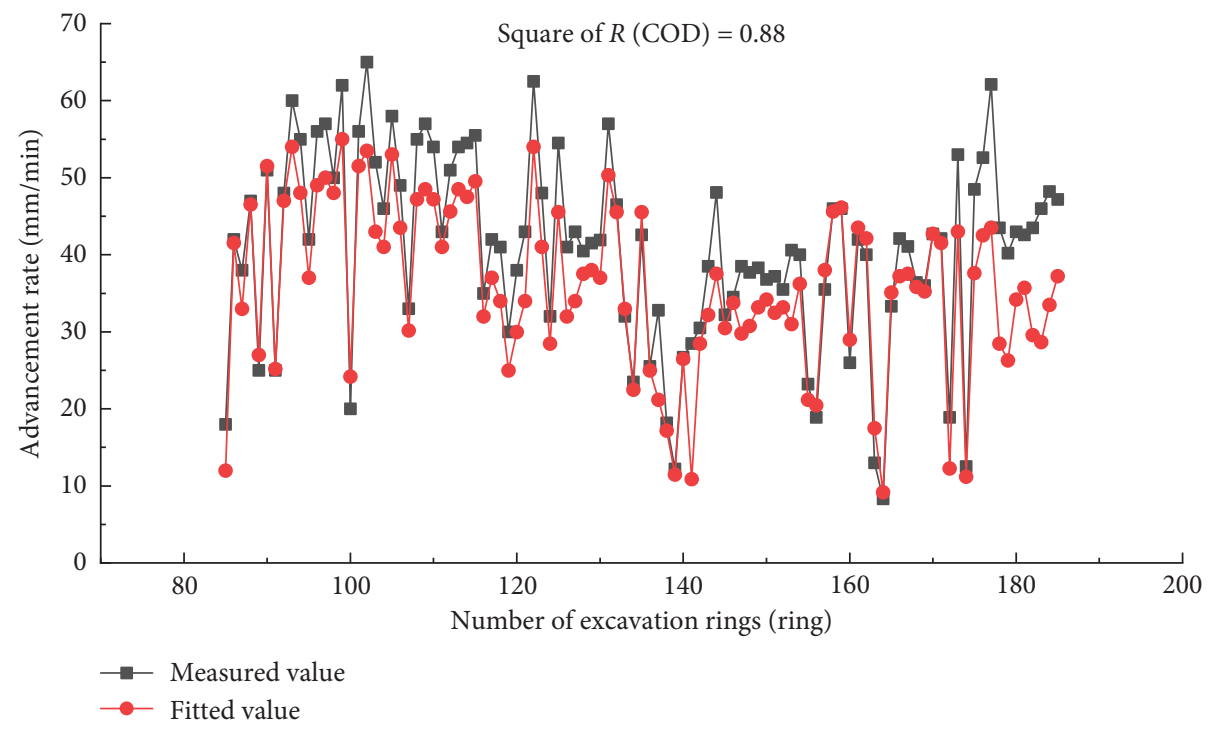

Figure 8: Comparisons between model calculation and measured data.

TABle 5: Comparison of measured and predicted lines.

\begin{tabular}{llccccccc}
\hline \multirow{2}{*}{} & \multirow{2}{*}{ Interval } & & \multicolumn{3}{c}{ Rate } \\
& & $0-10$ & $10-20$ & $20-30$ & $30-40$ & $40-50$ & $50-60$ & $60-70$ \\
\hline \multirow{2}{*}{ Right line } & Measured value & 0.024 & 0.040 & 0.156 & 0.146 & 0.191 & 0.345 \\
& Predictive value & 0.031 & 0.042 & 0.167 & 0.178 & 0.203 & 0.304 & 0.098 \\
\multirow{2}{*}{ Left line } & Measured value & 0.022 & 0.041 & 0.121 & 0.156 & 0.203 & 0.355 \\
& Predictive value & 0.020 & 0.039 & 0.122 & 0.147 & 0.242 & 0.335 \\
\hline
\end{tabular}

TABle 6: Comparison of measured and predicted lines.

\begin{tabular}{|c|c|c|c|c|c|c|c|}
\hline Date & $\begin{array}{c}\text { Cumulative number } \\
\text { (ring) }\end{array}$ & $\begin{array}{l}\text { Day number } \\
\text { (ring) }\end{array}$ & $\operatorname{Max}(\mathrm{mm} / \mathrm{min})$ & $\operatorname{Min}(\mathrm{mm} / \mathrm{min})$ & Mean $(\mathrm{mm} / \mathrm{min})$ & Std. dev. & Worktime $(\mathrm{mm})$ \\
\hline 2018-01-06 & 89 & 3 & 82 & 1 & 51.36 & 12.21 & 90.80 \\
\hline 2018-01-07 & 89 & 0 & - & - & - & - & - \\
\hline 2018-01-08 & 98 & 9 & 83 & 1 & 63.63 & 16.26 & 215.00 \\
\hline 2018-01-09 & 108 & 10 & 85 & 1 & 65.12 & 17.27 & 262.00 \\
\hline 2018-01-10 & 115 & 7 & 85 & 1 & 65.76 & 13.83 & 175.30 \\
\hline 2018-01-11 & 129 & 14 & 86 & 1 & 67.01 & 13.94 & 307.00 \\
\hline 2018-01-12 & 144 & 15 & 85 & 1 & 62.29 & 15.79 & 380.70 \\
\hline 2018-01-13 & 145 & 1 & 74 & 1 & 53.04 & 9.88 & 48.80 \\
\hline 2018-01-14 & 146 & 1 & 91 & 1 & 33.07 & 26.44 & 19.30 \\
\hline 2018-01-15 & 147 & 1 & 74 & 1 & 52.30 & 12.07 & 32.00 \\
\hline 2018-01-16 & 151 & 4 & 80 & 1 & 48.23 & 16.60 & 128.70 \\
\hline 2018-01-17 & 164 & 13 & 79 & 1 & 52.95 & 11.59 & 418.50 \\
\hline 2018-01-18 & 177 & 13 & 79 & 1 & 54.10 & 11.71 & 346.80 \\
\hline 2018-01-19 & 192 & 15 & 80 & 1 & 61.66 & 12.15 & 232.49 \\
\hline 2018-01-20 & 209 & 17 & 85 & 1 & 69.25 & 14.77 & 390.65 \\
\hline 2018-01-21 & 224 & 15 & 86 & 1 & 59.55 & 16.24 & 413.32 \\
\hline 2018-01-22 & 242 & 18 & 83 & 1 & 56.53 & 11.27 & 477.15 \\
\hline $2018-01-23$ & 243 & 1 & 64 & 1 & 56.83 & 5.76 & 28.17 \\
\hline 2018-01-24 & 243 & 0 & - & - & - & - & - \\
\hline 2018-01-25 & 254 & 11 & & & Abnormal data, remove & & \\
\hline 2018-01-26 & 264 & 10 & 75 & 1 & 47.30 & 14.59 & 133.33 \\
\hline 2018-01-27 & 280 & 16 & 75 & 1 & 50.96 & 9.64 & 492.65 \\
\hline 2018-01-28 & 295 & 15 & 78 & 1 & 50.09 & 9.50 & 474.81 \\
\hline 2018-01-29 & 309 & 14 & 79 & 1 & 53.69 & 11.55 & 417.15 \\
\hline
\end{tabular}


TABle 6: Continued.

\begin{tabular}{lcccccc}
\hline Date & $\begin{array}{c}\text { Cumulative number } \\
\text { (ring) }\end{array}$ & $\begin{array}{c}\text { Day number } \\
\text { (ring) }\end{array}$ & Max (mm/min) & Min (mm/min) & Mean (mm/min) & Std. dev. Worktime (mm) \\
\hline $2018-01-30$ & 327 & 18 & 83 & 1 & 56.76 & 12.31 \\
$2018-01-31$ & 341 & 14 & 74 & 1 & 45.55 & 501.15 \\
$2018-02-01$ & 351 & 10 & 78 & 1 & 52.45 & 8.45 \\
$2018-02-$ & 368 & 17 & 79 & 1 & 48.02 & 325.81 \\
02 & & & & & &
\end{tabular}

TABLE 7: Advancement time grouping table.

\begin{tabular}{lccc}
\hline Time group & Short advancement time & Medium advancement time & Long advancement time \\
\hline Range (minutes) & $0 \sim 30$ & $30 \sim 57$ & $57 \sim 84$ \\
\hline
\end{tabular}

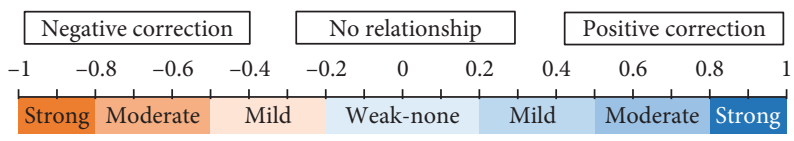

FIgURE 9: Correlation coefficient analysis chart of each group.

\begin{tabular}{|c|c|c|c|c|}
\hline \multicolumn{5}{|c|}{ Short advancement time } \\
\hline & Max & Mean & Std. dev. & Worktime \\
\hline Day pregress & 0.14 & 0.67 & $(0.14)$ & 0.85 \\
\hline Max & & $(0.41)$ & 0.83 & 0.27 \\
\hline Mean & & & $(0.77)$ & 0.70 \\
\hline Std. dev. & & & & $(0.25)$ \\
\hline
\end{tabular}

(a)

\begin{tabular}{|c|c|c|c|c|}
\hline \multicolumn{5}{|c|}{ Medium advancement time } \\
\hline & Max & Mean & Std. dev. & Worktime \\
\hline Day pregress & $(0.25)$ & $(0.11)$ & & 0.22 \\
\hline Max & & 0.98 & 0.55 & $(0.22)$ \\
\hline Mean & & & 0.36 & 0.85 \\
\hline Std. dev. & & & & $(0.09)$ \\
\hline
\end{tabular}

(b)

\begin{tabular}{|c|c|c|c|c|}
\hline \multicolumn{5}{|c|}{ Long advancement time } \\
\hline & Max & Mean & Std. dev. & Worktime \\
\hline Day pregress & 0.44 & 0.99 & 1.00 & 0.48 \\
\hline Max & & 0.99 & 1.00 & $(0.42)$ \\
\hline Mean & & & 1.00 & $(0.14)$ \\
\hline Std. dev. & & & & $(0.06)$ \\
\hline
\end{tabular}

(c)

FIGURE 10: Linear correlation evaluation chart.

at the shield initiation, normal excavation, and shield receiving phases is different. In order to show the construction organization of each phase clearly, the construction progress of the entire line under the engineering background is organized and plotted, as shown in Figures 11 and 12.

Shield tunneling in the interval can be divided into the four following stages: the initial stage, the normal excavation stage, the tool maintenance stage, and the receiving stage. At the beginning and receiving stages of the shield, it is necessary to pay close attention to the effect of end reinforcement to ensure that there is no leakage of water at the entrance of the tunnel. At the same time, both initial soil pressure establishment and receiving soil pressure reduction should be carried out gradually, so the advancement rate is slow, and the average does not exceed 5 rings/day.

Generally speaking, during the normal excavation phase of the shield, the average daily advancement of the two lines can reach more than 10 rings/day, achieving fast long-distance tunneling. The prediction model achieves good results. However, during the construction period, the left and right lines have been changing tools for about a month, extending the construction period. Therefore, in addition to increasing the advancement rate in actual construction, reasonable planning should be made in the early stage, the tool change distance should be prejudged, and the inspection well should be excavated in advance.

The earth pressure is 0.8 bar, the cutter head speed is $1.7 \mathrm{rpm}$, the total thrust is $24000 \mathrm{kN}$, the speed of the screw conveyor is $9 \mathrm{rpm}$, and the cutter head torque is $11000 \mathrm{kN} \cdot \mathrm{m}$. Substituting the above parameters in equation (4) produces $v=36.93 \mathrm{~mm} / \mathrm{min}$, which is close to the average rate of the normal advancement stage of $40 \mathrm{~mm} / \mathrm{min}$. The prediction error is $7.6 \%$, which is within the allowable range. Therefore, the values of the above parameters can ensure the safe and rapid long-distance tunneling. 


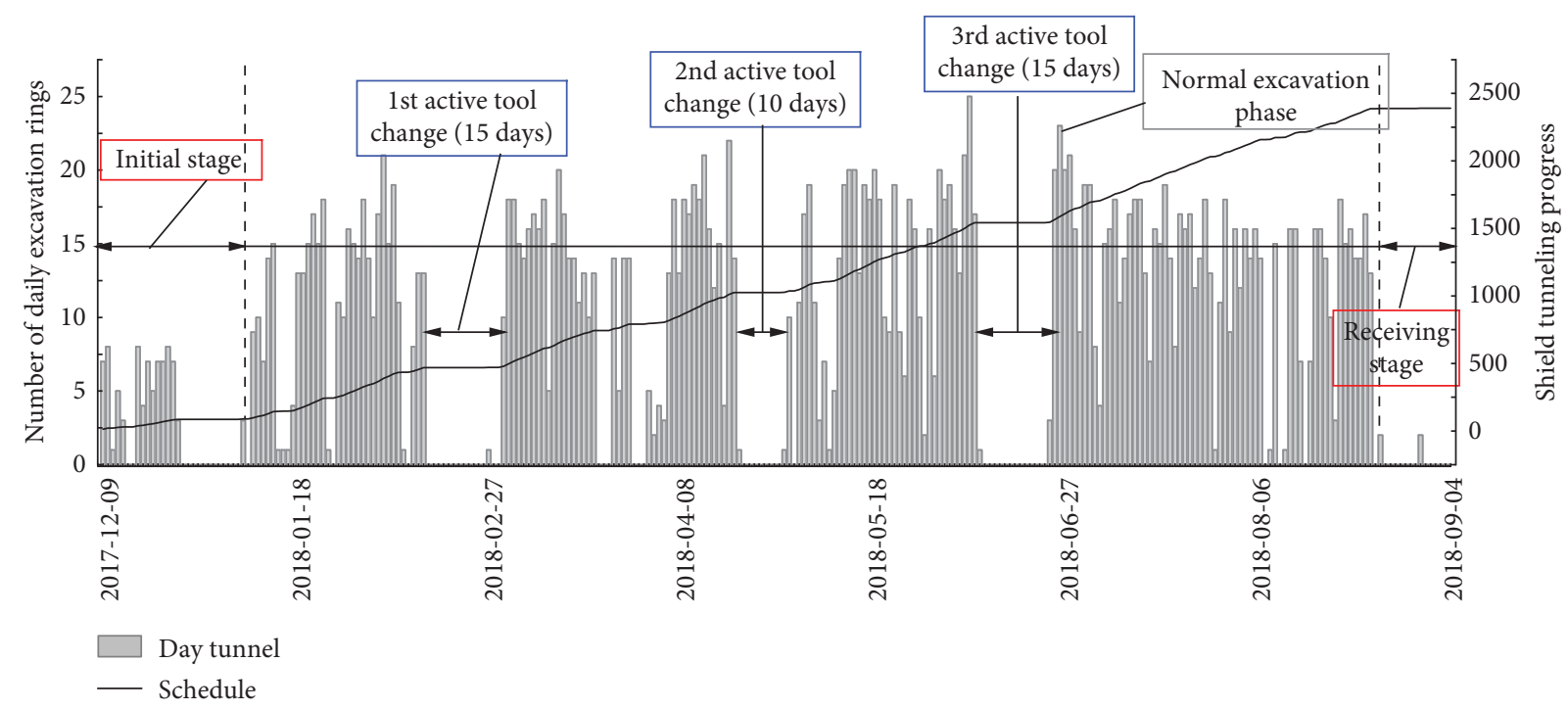

Figure 11: Construction schedule map of left line of interval.

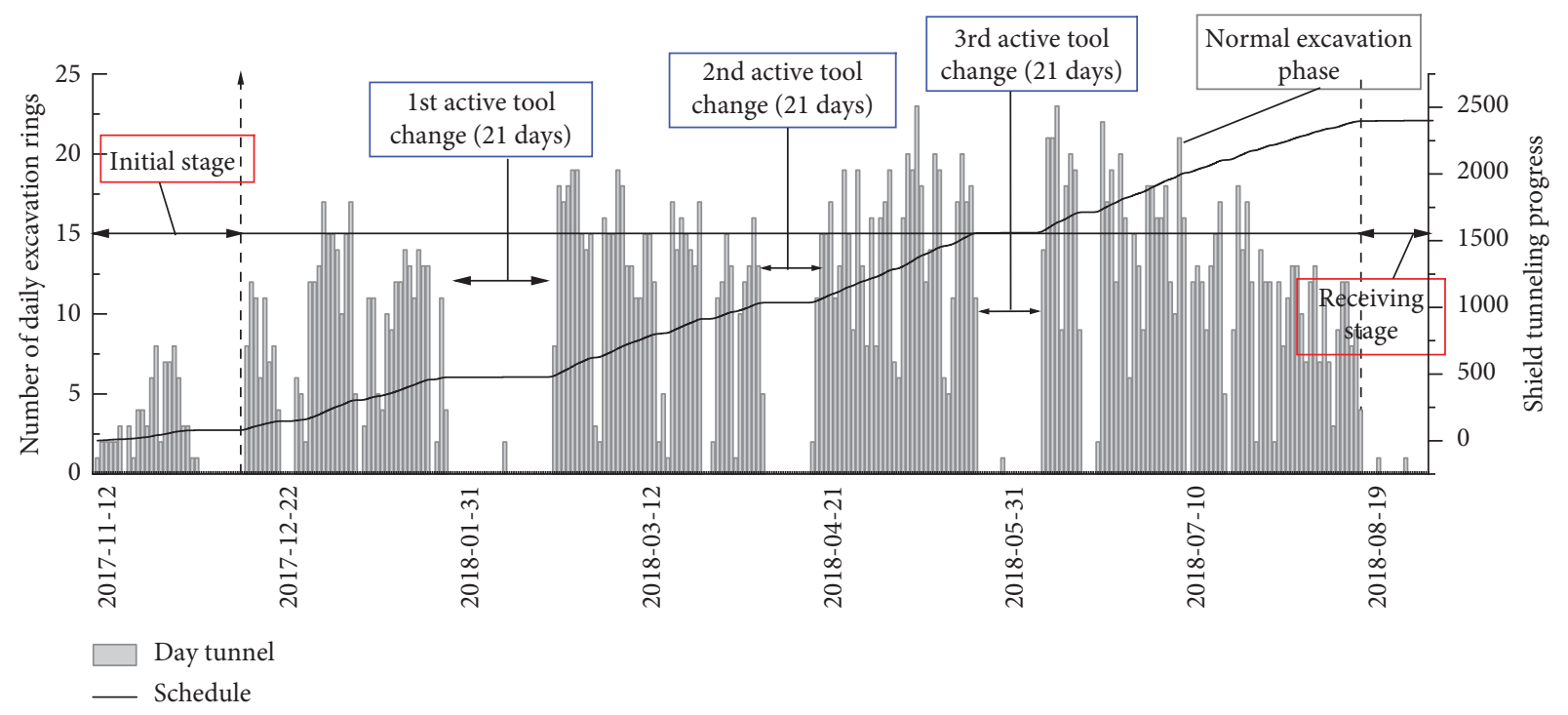

FIGURE 12: Construction schedule map of right line of interval.

\section{Conclusion}

In this paper, a prediction model of the advancement rate of the earth pressure balance shield in the sandy cobble ground is obtained, and the influence of the main operational parameters on the shield advancement rate is studied. The verified relationship is established and applied to the advancement rate analysis during the construction progress of a new airport line. It is believed that this research lays the foundation for future shield advancement rate prediction, safety control, and parameter optimization of similar projects. The main results are as follows:

(1) A shield advancement rate prediction model is constructed through multiple regressions. The fitting accuracy is high and close to reality, which can provide a reference for the construction of similar strata-related models. The optimum parameters for shield advancement in the research project are the earth pressure of $0.7 \sim 0.9$ bar, cutter head speed of $1.675 \sim 1.725 \mathrm{rpm}$, total thrust of $21000 \sim 24000 \mathrm{kN}$, screw conveyor speed of $9 \sim 10 \mathrm{rpm}$, and torque of $10000 \sim 11000 \mathrm{kN} \cdot \mathrm{m}$.

(2) There is a linear relationship between the advancement rate and penetration, while other operational parameters are not linearly related to the advancement rate. When these parameters are controlled in the optimal interval, rapid long-distance tunneling can be achieved under the premise of safety. The order of influence of the four operational parameters on the advancement rate is as follows: total thrust, cutter head torque, screw conveyor speed, and cutter head speed. 
(3) By grouping the daily advancement rate during onsite construction, the relationships between daily progress and the maximum rate, minimum rate, average rate, standard deviation of rate, and daily advancement time are studied. It is found that when the daily advancement time is greater than 57 minutes, there is a strong linear correlation between the advancement rate and the daily progress, which verifies the prediction of overall progress based on the advancement rate.

In the process of establishing the prediction model for the advancement rate in Beijing sandy cobble ground, the influences of tunnel geometrical condition and geological and geotechnical condition have not been quantified in depth. On the basis of the established prediction model, the overall progress prediction model of the shield can be further established considering the influence of active tool change. More work will be conducted on the above aspects.

\section{Data Availability}

The data used to support the findings of this study are available from the first author upon request.

\section{Conflicts of Interest}

The authors declare that they have no conflicts of interest.

\section{Acknowledgments}

The present work was supported by the National Natural Science Foundation of China (U1261212).

\section{References}

[1] P. Cheng, X. Zhuang, H. Zhu, and Y. Li, “The construction of equivalent particle element models for conditioned sandy pebble," Applied Sciences, vol. 9, no. 6, Article ID 1137, 2019.

[2] Y. Wei, Y. Yang, M. Tao, D. Wang, and Y. Jie, "Earth pressure balance shield tunneling in sandy gravel deposits: a case study of application of soil conditioning," Bulletin of Engineering Geology and the Environment, vol. 79, no. 9, pp. 5013-5030, 2020.

[3] B. Zhao, D. Liu, and B. Jiang, "Soil conditioning of waterless sand-pebble stratum in EPB tunnel construction," Geotechnical and Geological Engineering, vol. 36, no. 4, pp. 2495-2504, 2018.

[4] A. Sirivachiraporn and N. Phienwej, "Ground movements in EPB shield tunneling of bangkok subway project and impacts on adjacent buildings," Tunnelling and Underground Space Technology, vol. 30, pp. 10-24, 2012.

[5] E. Farrokh and J. Rostami, "Correlation of tunnel convergence with TBM operational parameters and chip size in the Ghomroud tunnel, Iran," Tunnelling and Underground Space Technology, vol. 23, no. 6, pp. 700-710, 2008.

[6] Z.-H. Huang, Y.-M. Hou, Y.-N. Ren, and J.-H. Wang, "Environmental effect and control of large diameter EPB shield tunneling below an operating airport," Journal of Aerospace Engineering, vol. 28, no. 6, Article ID A4014004, 2015.

[7] S. G. Ercelebi, H. Copur, and I. Ocak, "Surface settlement predictions for Istanbul metro tunnels excavated by EPB-
TBM," Environmental Earth Sciences, vol. 62, no. 2, pp. 357-365, 2010.

[8] Z. X. Zhang, H. Zhang, and J. Y. Yan, "A case study on the behavior of shield tunneling in sandy cobble ground," Environmental Earth Sciences, vol. 69, no. 6, pp. 1891-1900, 2012.

[9] K. Zhang, J. L. Chavez Torres, and Z. Zang, "Numerical analysis of pipelines settlement induced by tunneling," $A d$ vances in Civil Engineering, vol. 2019, Article ID 4761904, 10 pages, 2019.

[10] N.-A. Do, D. Dias, P. Oreste, and I. Djeran-Maigre, "Threedimensional numerical simulation of a mechanized twin tunnels in soft ground," Tunnelling and Underground Space Technology, vol. 42, no. 11, pp. 40-51, 2014.

[11] W. Qian, T. Qi, Y. Zhao, Y. Le, and H. Yi, "Deformation characteristics and safety assessment of a high-speed railway induced by undercutting metro tunnel excavation," Journal of Rock Mechanics and Geotechnical Engineering, vol. 11, no. 1, pp. 88-98, 2019.

[12] H. Cheng, J. Chen, and G. Chen, "Analysis of ground surface settlement induced by a large EPB shield tunnelling: a case study in Beijing, China," Environmental Earth Sciences, vol. 78, no. 20, p. 605, 2019.

[13] W. Qi, Z. Yang, Y. Jiang, Z. Liu, Y. Guo, and X. Yang, "Risk mitigation and construction control for effective underwater recovery of an EPB shield: a case study of the first metro tunnel in Tel Aviv," Advances in Civil Engineering, vol. 2020, Article ID 6049608, 15 pages, 2020.

[14] N. Zhang, S.-L. Shen, A. Zhou, and Y.-F. Jin, "Application of LSTM approach for modelling stress-strain behaviour of soil," Applied Soft Computing, vol. 100, no. 10, Article ID 106959, 2021.

[15] N. Kardani, A. Zhou, M. Nazem, and S.-L. Shen, "Improved prediction of slope stability using a hybrid stacking ensemble method based on finite element analysis and field data," Journal of Rock Mechanics and Geotechnical Engineering, vol. 13, no. 1, pp. 188-201, 2021.

[16] K. Zhang, H.-M. Lyu, S.-L. Shen, A. Zhou, and Z.-Y. Yin, "Evolutionary hybrid neural network approach to predict shield tunneling-induced ground settlements," Tunnelling and Underground Space Technology, vol. 106, Article ID 103594, 2020.

[17] N. Zheng, X. Zhigang, S. Gang et al., "Design of a new multispectral waveform LiDAR instrument to monitor vegetation," IEEE Geoscience and Remote Sensing Letters, vol. 12, no. 7, pp. 1506-1510, 2015.

[18] X. Liu, C. Shao, H. Ma, and R. Liu, "Optimal earth pressure balance control for shield tunneling based on LS-SVM and PSO," Automation in Construction, vol. 20, no. 4, pp. 321-327, 2011.

[19] Y. Zhang, Z. Zhang, S. Xue, R. Wang, and M. Xiao, "Stability analysis of a typical landslide mass in the three gorges reservoir under varying reservoir water levels," Environmental Earth Sciences, vol. 79, no. 1, p. 42, 2020.

[20] A. Teymen and E. C. Mengüç, "Comparative evaluation of different statistical tools for the prediction of uniaxial compressive strength of rocks," International Journal of Mining Science and Technology, vol. 30, no. 6, pp. 785-797, 2020.

[21] S. A. Saki, J. F. Brune, and M. U. Khan, "Optimization of gob ventilation boreholes design in longwall mining," International Journal of Mining Science and Technology, vol. 30, no. 6, pp. 811-817, 2020.

[22] Y.-G. Zhang, J. Tang, Z.-Y. He, J. Tan, and C. Li, “A novel displacement prediction method using gated recurrent unit 
model with time series analysis in the Erdaohe landslide," Natural Hazards, vol. 105, no. 1, pp. 783-813, 2020.

[23] U. Ates, N. Bilgin, and H. Copur, "Estimating torque, thrust and other design parameters of different type TBMs with some criticism to TBMs used in Turkish tunneling projects," Tunnelling and Underground Space Technology, vol. 40, pp. 46-63, 2014.

[24] Q. Zhang, Z. Liu, and J. Tan, "Prediction of geological conditions for a tunnel boring machine using big operational data," Automation in Construction, vol. 100, pp. 73-83, 2019.

[25] P. Wang, X. Kong, Z. Guo, and L. Hu, "Prediction of axis attitude deviation and deviation correction method based on data driven during shield tunneling," IEEE Access, vol. 7, pp. 163487-163501, 2019.

[26] S.-S. Lin, S.-L. Shen, N. Zhang, and A. Zhou, "Modelling the performance of EPB shield tunnelling using machine and deep learning algorithms," Geoscience Frontiers, vol. 12, no. 5, Article ID 101177, 2021.

[27] W. Su, X. Li, D. Jin, Y. Yang, R. Qin, and X. Wang, "Analysis and prediction of TBM disc cutter wear when tunneling in hard rock strata: a case study of a metro tunnel excavation in Shenzhen, China," Wear, vol. 446-447, Article ID 203190, 2020.

[28] D. Kim, K. Pham, S. Park, J. Y. Oh, and H. Choi, "Determination of effective parameters on surface settlement during shield TBM," Geomechanics and Engineering, vol. 21, no. 2, pp. 153-164, 2020.

[29] K. Elbaz, S.-L. Shen, A. Zhou, Z.-Y. Yin, and H.-M. Lyu, "Prediction of disc cutter life during shield tunneling with AI via the incorporation of a genetic algorithm into a GMDHtype neural network," Engineering, vol. 7, no. 2, pp. 238-251, 2021.

[30] K. Elbaz, S.-L. Shen, W.-C. Cheng, and A. Arulrajah, "Cutterdisc consumption during earth pressure balance tunnelling in mixed strata," Proceedings of the Institution of Civil Engineers Geotechnical Engineering, vol. 171, no. 4, pp. 363-376, 2018. 